\title{
Is There A Mortality Effect of Emipiric Colistin In The
}

\section{Treatment of Acinetobacter Baumanni?}

\author{
IIIhan Bahar $^{1^{*}}$, Gülseren Elay ${ }^{2}$ \\ ${ }^{1}$ İlhan Katip Celebi University, Atatürk Education and Research Hospital Internal Intensive Care, Izmir, Turkey \\ ${ }^{2}$ Ersin Aslan Training and Research Hospital Intensive Care Anesthesiology, Gaziantep, Turkey
}

\begin{abstract}
To investigate the effect of empirical or culture based colistin therapy on the mortality of intensive care medicine (ICU) patients with severe sepsis and septic shock.

Patients treated in three Intensive Care Units of medical faculty of Erciyes University were included in this retrospective, descriptive study.

The groups did not differ regarding the mean duration of intensive care stay ( 15 days vs. 20 days, $p=0.20)$ or in terms of the intensive care mortality $(58.3 \%$ vs. $72.7 \%, \mathrm{p}=0.31)$. There was also no difference between the groups in 30 -day in hospital mortality $(61.1 \%$ vs. $78.8 \%, \mathrm{p}=0.12)$.

In patients with severe sepsis/septic shock, there were no differences between the groups in which the colistin therapy was initiated empirically or based on sensitivity test results.
\end{abstract}

Key Words: Sepsis, Acinetobacter baumannii, colistin, mortality

\section{Introduction}

Carbapenem resistant Acinetobacter baumannii (CRAB) infections as the cause frequent in Turkey (14). Polymyxin E (kolistimetfat) is the most and last step drug in $\mathrm{CRAB}$ treatment (5). In some studies, it is mentioned that CRAB infection does not contribute to mortality and is caused by underlying disease. (6-8). Sepsis is an abnormal inflammatory response to infection. Sepsis can cause tissue and organ damage (9-10). Early antibiotic treatment is recommended (11). However, clinicians have question marks in their minds during the initiation of empirical colistin therapy.

Since the exact therapeutic dose of colistin for the treatment of CRAB is not known (12-18) current studies are limited, and the potential development of resistance to colistin has been recently reported, clinicians may prefer to initiate the therapy based on sensitivity test results instead of administering the drug empirically.

In our study, we aimed to investigate whether CRAB affects mortality in cases treated with colistin initiated based on culture results or empirically in severe sepsis/septic shock, which involve organ failure and persistent hypotension despite fluid administration.

\section{Materials and Methods}

Study Design Population: The data were obtained by scanning the patients in the intensive care unit of Erciyes University Hospital between 01.01.201601.01.2017 and retrospectively in electronic and/or files. The approval of the ethics committee was obtained with the decision no: 2016/298. Patients who received colistin for severe sepsis and septic shock were included in the study. Definition of sepsis was made according to 2013 sepsis guide. Infection definitions were taken according to IDSA (infectious diseases society of America guidelines) (19). Empiric treatment is initiated by an infectious disease specialist.

Patients in the empiric group were negative for culture-negative sepsis and the most likely microorganism was considered as MDRAB and treatment was started. Patients receiving CRRT and inhaler colistine were excluded from the study. Those who had been immunosuppressed, without life expectancy, those in whom the colistin therapy had been administered for less than three days, and those in whom the colistin therapy had been initiated but no growth had been detected in the culture were excluded from the study. Adult (aged $\geq 18$ years) patients with CRAB infections who had received polymyxin $\mathrm{E}$ for $\geq 72$ hours were included in the study. This test was also used in the group of empiric 


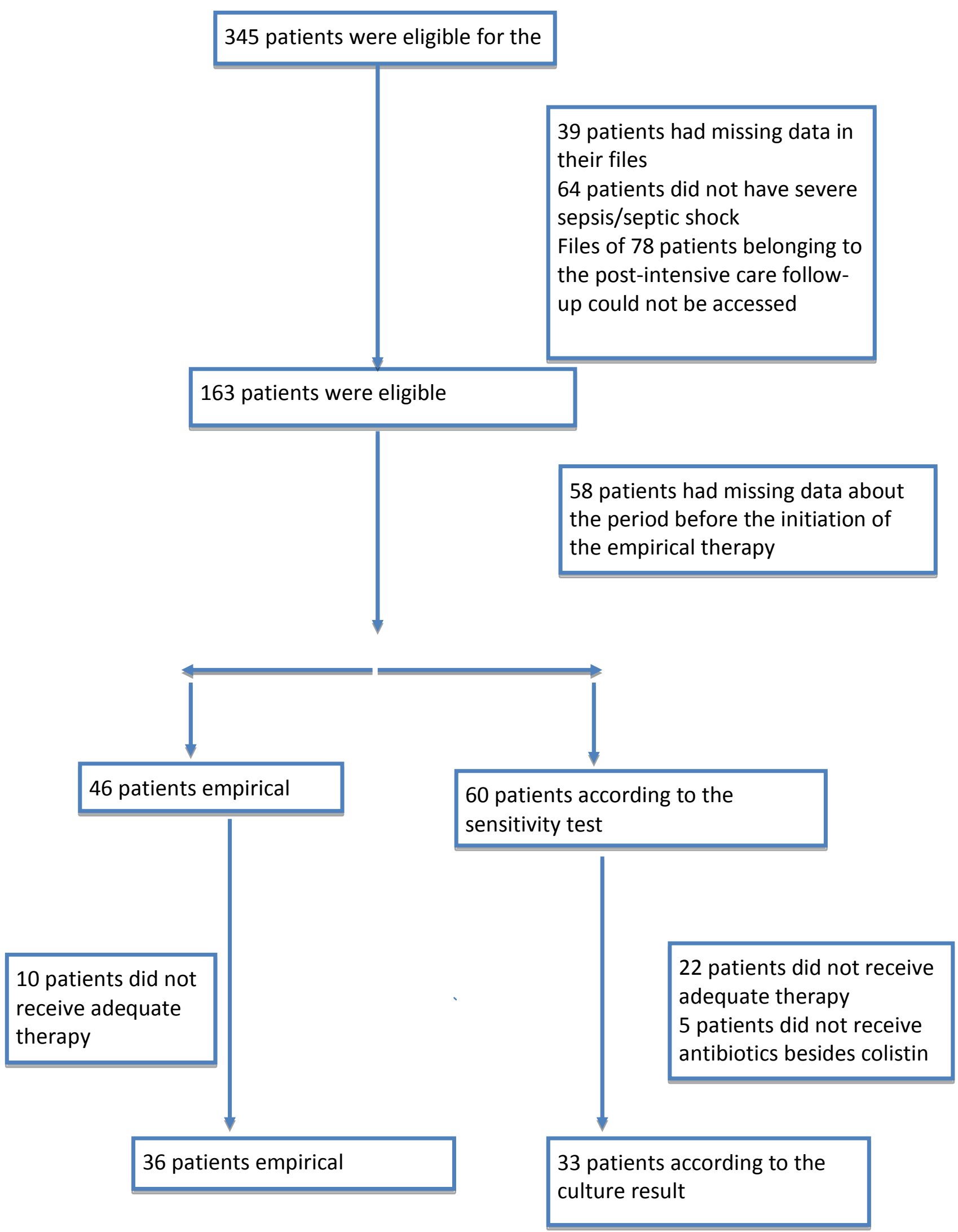

East J Med Volume:24, Number:4, October-December/2019 

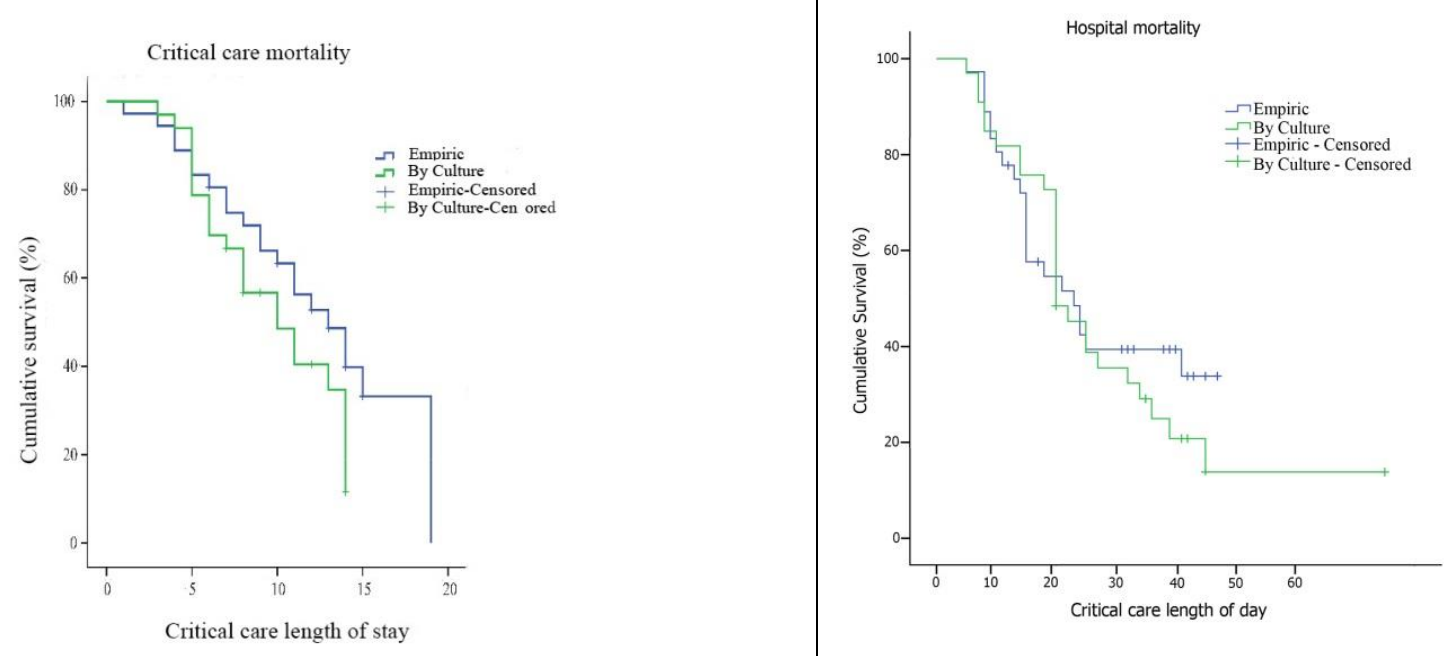

Fig. 2 and 3. Intensive care and hospital mortality in the Kaplan Meier curve

colistin and subsequently acinetobacter baumannii.

Data Collection: Patient information was collected as shown in Figure 1.

The data obtained included the demographics of patients, baseline APACHE II scores, inflammatory markers immediately before and 5 days after the initiation of colistin therapy, SOFA scores, creatinine levels, norepinephrine levels, numbers of mechanical ventilator-free days after the initiation of colistin therapy, noradrenaline min-max levels, nephrotoxicity, duration of colistin therapy, length of intensive care unit (ICU) stay, the day on which the colistin therapy was initiated, CRAB growth sites, intensive care locations, the antibiotics added to the colistin therapy, and the intensive care and 30-day hospital mortalities.

Microbiology: Microbiology reports for CRAB were obtained by examining the medical records between January 2015 and January 2016.Sensitivity to antibiotics was determined using the VITEK $\mathrm{R} 2$ system (bioMérieux) and the analytical software that determines resistance phenotypes (version R7.01); the E-test method was used to confirm the resistance to Tigecycline and polymyxin B.

Administration of Colistin: The administered drug was Colimycin (colistimethate sodium; KocakFarma, Istanbul, Turkey). After the loading dose of $450 \mathrm{mg}$, a maintenance dose of $80-240 \mathrm{mg}$ was administered three times daily. Colistin was given in $100 \mathrm{ml}$ saline over 15 minutes.

If the patient's creatinine clearance $(\mathrm{Crcl})$ level was higher than $80 \mathrm{ml} / \mathrm{min}$., $5 \mathrm{mg} / \mathrm{kg} /$ day colistin was administered. If $\mathrm{Crcl}$ was $30-80 \mathrm{ml} / \mathrm{min}$., $2.5 \mathrm{mg} / \mathrm{kg} / \mathrm{day}$ was administered. If $\mathrm{CrCl}$ was lower than $30 \mathrm{ml} / \mathrm{min}, 1-1.5 \mathrm{mg} / \mathrm{kg} /$ day was administered.
$\mathrm{CrCl}$ was calculated using the Cockcroft-Gault formula. Dose adjustments were based on the Nosocomial Infection Control Committee's recommendations. $80-160 \mathrm{mg}$ was administered following hemodialysis.

Statistical Analysis: Evaluation of the data was performed using the IBM SPSS Statistics 22.0 (IBM Corp., Armonk, New York, US) statistical package software. The number of units $(n)$, percentage $(\%)$, mean \pm standard deviation $(\bar{x} \pm s d)$ median $\left(25^{\text {th }}\right.$ $75^{\text {th }}$ percentile) values were presented as descriptive statistics. Normal distribution of the data for numerical variables was evaluated using the ShapiroWilk normality test and Q-Q plots. Comparison of numerical variables between the empirical and definitive groups was performed using the MannWhitney $U$ test. When there were more than two groups, inter-group comparisons were performed using the one-sided variance analysis for normally distributed variables, and the Tukey's HSD test was used for multiple comparisons. For non-normally distributed variables, inter-group comparisons were performed using the Kruskal-Wallis analysis. If a difference was found with the Kruskal-Wallis analysis, the Dunn-Bonferroni test was used as the multiple comparison tests. The life expectancy was evaluated using the Kaplan-Meier method. The relationships between categorical variables were examined using the exact Chi-Square method. $P<0.05$ was considered statistically significant.

\section{Results}

A total of sixty-nine patients were included in the study. The empirical group (Group 1) consisted of 33 
Table 1: Demographic data

\begin{tabular}{|c|c|c|c|}
\hline & Empirical therapy & By culture & $\mathrm{p}<0.05$ \\
\hline Number (\%) & 36 & 33 & \\
\hline Male gender & 15 & 12 & 0.85 \\
\hline \multicolumn{4}{|l|}{ Median (interquartile range) } \\
\hline Age (years) & $63.5(54-76)$ & $58.6(43-73)$ & 0.76 \\
\hline Weight , Kg & $80.0(70-80)$ & $75(50-120)$ & 0.55 \\
\hline Height, cm & $162(160-175)$ & $170(150-180)$ & 0.50 \\
\hline APACHE II & $23(18-30)$ & $19(14-25)$ & 0.01 \\
\hline SOFA previous value from the start of treatment & $7(5-10)$ & $8(5-10)$ & 0.92 \\
\hline PCT previous value from the start of treatment $(\mu \mathrm{g} / \mathrm{L})$ & $5(2-12)$ & $3(1.5-62)$ & 0.26 \\
\hline CRP prior to initiating therapy $(\mathrm{mg} / \mathrm{L})$ & $129(80-218)$ & $80(33-138)$ & 0.02 \\
\hline Creatinine previous to starting treatment $(\mathrm{mg} / \mathrm{dL})$ & $1.3(0.9-2.5)$ & $0.9(0.5-2.0)$ & 0.10 \\
\hline SOFA5th day after the initiation of therapy & $9(6-11)$ & $9(5-11)$ & 0.84 \\
\hline PCT 5th day after the initiation of therapy & $4(1-10)$ & $2(1-5)$ & 0.52 \\
\hline CRP 5th day after the initiation of therapy & $122(30-205)$ & $130(20-207)$ & 0.78 \\
\hline Creatine 5 th day after the initiation of therapy & $1.5(0.8-2.1)$ & $1.0(0.6-2.2)$ & 0.25 \\
\hline Nephrotoxicity after the initiation of treatment & $11(\% 30)$ & $9(\% 27)$ & 0.79 \\
\hline $\begin{array}{l}\text { Dose of noradrenaline prior to the initiation of } \\
\text { treatment }(\mathrm{mcg} / \mathrm{kg} / \mathrm{min})\end{array}$ & $0.1(0.05-1.5)$ & $0.1(0.07-1.2)$ & 0.44 \\
\hline $\begin{array}{l}\text { Noradrenaline value after starting treatment } \\
(\mathrm{mcg} / \mathrm{kg} / \mathrm{min})\end{array}$ & $0.1(0.0-0.1)$ & $0.0(0.0-0.4)$ & 0.11 \\
\hline $\begin{array}{l}\text { Mechanical ventilation after starting treatment free } \\
\text { days }\end{array}$ & $2(0-5)$ & $0(0-5)$ & 0.28 \\
\hline Treatment days(days) & $11(7-14)$ & $11(7-14)$ & 0.12 \\
\hline ICU length of stay (days) & $15(10-23)$ & $20(12-26)$ & 0.20 \\
\hline $\begin{array}{l}\text { Which day of hospitalization in intensive care } \\
\text { treatment is started (day) }\end{array}$ & $5(2-13)$ & $12(5-20)$ & 0.02 \\
\hline The site of CRAB growth & & & 0.01 \\
\hline Blood & $3(4 \%)$ & $16(23 \%)$ & \\
\hline Lung & $33(47 \%)$ & $16(23 \%)$ & \\
\hline Urinary & $0(0 \%)$ & $1(1 \%)$ & \\
\hline The site of admission to intensive care & & & 0.30 \\
\hline Post op. & $0(0 \%)$ & $7(10 \%)$ & \\
\hline Another hospital & $4(5 \%)$ & $4(5 \%)$ & \\
\hline
\end{tabular}


Services

Emergency

Second antibiotic

Carbapenem

Cefepime

Piperacillin/tazobactam

Sulbactam

ICU mortality (n, \%)

30-day mortality (n; \%)

(47\%) patients while Group 2, in whom the therapy was initiated based on antibiotic sensitivity test results, consisted of 36 (53\%) patients. The median ages in the empirical and sensitivity test groups were 63.5 and 58.6 years respectively $(\mathrm{p}=0.76)$. There were no differences between the groups regarding the demographics. The mean APACHE II score was higher in the empirical therapy group. There were differences between the two groups in terms of days on which antibiotics were started $(p=0.02)$, and there were differences in terms of cultural breeding ground $(p=0.01)$. There was no difference between the two groups for other parameters (Table 1) There were no intensive care unit and 30-day mortality difference for both groups (Figure 2 and 3).

\section{Discussion}

We found no differences regarding intensive care mortality and 30-day hospital mortality between the groups in which colistin was initiated empirically and based on the sensitivity test results. However, studies reported inconsistent results regarding the contribution of $\mathrm{AB}$ infection to mortality $(6-8,20)$. There have been some studies which indicated that $\mathrm{AB}$ infection has no effect on mortality as well as others which reported that $\mathrm{AB}$ had contributed to mortality. The number of studies was small and the fact that they were conducted in small and heterogeneous populations might have caused this inconsistency (21). The main determinant of mortality was attributed to the severity of the underlying disease in the studies that had suggested that $A B$ infection contributed to mortality (1). AB displays mechanisms of resistance to all existing antibiotic classes and causes outbreaks with these multidrug-resistant strains. Studies which had investigated the contribution of $\mathrm{ABs}$ to increased virulence to mortality reported inconsistent results (22).
Sunenshine et al. divided their patients into three groups in their study. They compared those infected with MDR $\mathrm{AB}$ to those with positive sensitivity test results and those who were colonized; there were no differences between those who were colonized. They found increased durations of ICU and hospital stays in MDRABs. Sunenshine et al. found that ABs did not increase mortality, even when they were multidrug-resistant. However, their study included very few patients with severe sepsis/septic shock. In our study, durations of intensive care and hospital stay were not increased in the group in which antibiotics were initiated based on sensitivity test results. The studies reporting that $\mathrm{MDR} A B$ can increase mortality in sepsis patients are limited (23). Our study will shed light on this. The guidelines published by the European Intensive Care Society recommend early empirical treatment in severe infections with Carbapenem-resistant AB. Since the studies on MDR are limited and samples are small, this recommendation is controversial. The limitation of our study is that growth in the lungs was more common in the empirical treatment group (47\%). Since the lung penetration of colistin is not exactly known, the treatment of ventilator-associated pneumonia, which is defined as the new or progressive infiltration in patients who were mechanically ventilated for longer than 48 hours with increased neutrophils and the growth of pathogens at the pre-specified threshold values in the respiratory sample, is controversial (24-26); this might have caused the uncertainty of the treatment observed in the empirical group. Our study has some limitations. Since our study was a retrospective and single-center study, it is not representative of all other organizations in this respect. A multi-center study should therefore be conducted with a larger number of patients. 
Turkey Acinetobacter is endemic with baumanni and colistin is generally used in treatment. Colistine is one of the last drugs. There was no difference between severe sepsis/septic shock emprical initiation and cultural initiation.

Conflict of Interest: Authors declared no conflict of interest or financial support

\section{References}

1. Di Popolo A, Giannouli M, Triassi M, Brisse S, Zarrilli R. Molecular epidemiological investigation of multidrug-resistant Acinetobacter baumannii strains in four Mediterranean countries with a multilocus sequence typing scheme. Clin Microbiol Infect 2011; 17: 197-201.

2. Meric M, Kasap M, Gacar G, et al. Emergence and spread of carbapenem-resistant Acinetobacter baumannii in a tertiary care hospital in Turkey. FEMS Microbiol Lett 2008; 282: 214-218.

3. Perez F, Hujer AM, Hujer KM, Decker BK, Rather PN, Bonomo RA. Global challenge of multi drug-resistant Acinetobacter baumannii. Antimicrob Agents Chemother 2007; 51: 34713484.

4. Poirel L, Nordmann P. Carbapenem resistance in Acinetobacter baumannii: mechanisms and epidemiology. Clin Microbiol Infect 2006; 12: 826-836.

5. Biswas S, Brunel JM, Dubus JC, ReynaudGaubert M, Rolain JM. Colistin: an update on the antibiotic of the 21 st century. Expert Rev Anti Infect Ther 2012; 10: 917-934.

6. Garnacho J, Sole-Violan J, Sa-Borges M, Diaz E, Rello J. Clinical impact of pneumonia caused by Acinetobacter baumannii in intubated patients: a matched cohort study. Crit Care Med 2003; 31: 2478-2482.

7. Blot S, Vandewoude K, Colardyn F. Nosocomial bacteremia involving Acinetobacter baumannii in critically ill patients: a matched cohort study. Intensive Care Med 2003; 29: 471-475.

8. Falagas ME, Rafailidis PI. Attributable mortality of Acinetobacter baumannii: no longer a controversial issue. Crit Care 2007; 11: 134.

9. Murphy SL, Xu J, Kochanek KD. Deaths: final data for 2010. Natl Vital Stat Rep 2013; 61: 1-117.

10. Joly-Guillou ML, Wolff M, Pocidalo JJ, Walker F, Carbon C. Use of a new mouse model of Acinetobacter baumannii pneumonia to evaluate the postantibiotic effect of imipenem. Antimicrob Agents Chemother 1997; 41: 345-351.

11. Dellinger RP, Levy MM, Rhodes A, et al. Surviving Sepsis Campaign: international guidelines for management of severe sepsis and septic shock, 2012. Intensive Care Med 2013; 39: 165-228.
12. Michalopoulos AS, Falagas ME. Colistin: recent data on pharmacodynamics properties and clinical efficacy in critically ill patients. Ann Intensive Care 2011; 1: 30.

13. Lu Q, Girardi C, Zhang M, et al. Nebulized and intravenous colistin in experimental pneumonia caused by Pseudomonas aeruginosa. Intensive Care Med 2010; 36(7): 1147-1155.

14. Trotman RL, Williamson JC, Shoemaker DM, Salzer WL. Antibiotic dosing in critically ill adult patients receiving continuous renal replacement therapy. Clin Infect Dis 2005; 41: 1159-1166.

15. Fishbain J, Peleg AY. Treatment of Acinetobacter infections. Clin Infect Dis 2010; 51: 79-84.

16. Nation RL, Garonzik SM, Li J, et al. Updated US and European dose recommendations for intravenous colistin: how do they perform? Clin Infect Dis 2016; 62: 552-558.

17. Pogue JM, Ortwine JK, Kaye KS. Editorial commentary: Optimal usage of colistin: are we any closer? Clin Infect Dis 2015; 61: 1778-1780.

18. Jones CL, Clancy M, Honnold C, et al. Fatal outbreak of an emerging clone of extensively drug-resistant Acinetobacter baumannii with enhanced virulence. Clin Infect Dis 2015; 61: 145154.

19. Martin-Loeches I, Deja M, Koulenti D, et al. Potentially resistant microorganisms in intubated patients with hospital-acquired pneumonia: the interaction of ecology, shock and risk factors. Intensive Care Med 2013; 39: 672-681.

20. Robenshtok E, Paul M, Leibovici L, et al. The significance of Acinetobacter baumanniibacteraemia compared with Klebsiella pneumoniae bacteraemia: risk factors and outcomes. J Hosp Infect 2006; 64: 282-287.

21. Abbo A, Carmeli Y, Navon-Venezia S, SiegmanIgra Y, Schwaber MJ. Impact of multi-drugresistant Acinetobacter baumannii on clinical outcomes. Eur J Clin Microbiol Infect Dis 2007; 26: 793-800.

22. Inchai J, Pothirat C, Bumroongkit C, Limsukon A, Khositsakulchai W, Liwsrisakun C. Prognostic factors associated with mortality of drug-resistant Acinetobacter baumannii ventilator-associated pneumonia. J Intensive Care 2015; 3: 9.

23. Sunenshine RH, Wright MO, Maragakis LL, et al. Multidrug-resistant Acinetobacter Infection Mortality Rate and Length of Hospitalization. Emerg Infect Dis 2007; 13: 97-103.

24. Garnacho-Montero J, Dimopoulos G, Poulakou $G$, et al. Task force on management and prevention of Acinetobacter baumannii infections in the ICU. Intensive Care Med 2015; 41: 2057 2075.

25. Çakan MZ, Demirkıran H. (2018). Ventilatör ilişkili pnömoni önleme paketine uyumun arttırılmasının ventilatör ilişkili pnömoni üzerine 
etkisi. Uzmanlı Tezi. Van Yüzüncü Yıl Üniversitesi, Van.

26. Michalopoulos A, Fotakis D, Virtzili S, et al. Aerosolized colistin as adjunctive treatment of ventilator-associated pneumonia due to multidrug-resistant Gram-negative bacteria: a prospective study. Respir Med 2008; 102: 407-412 